\title{
Current Problems and Challenges in Non-university Tertiary Mathematics Education (NTME)
}

\author{
James Roznowsk and Huei Wuan Low-Ee
}

\section{Report}

The countries represented during the discussion group's meetings included: Australia, Canada, China, Iran, Israel, Philippines, Singapore, the United Arab Emirates, and the United States. The types of institutions varied among the countries and included: two and four-year vocational institutions, community colleges, programs related to retraining adults, and a one-year preparatory program in Israel for individuals coming out of military service and interested in attending university.

The discussion group team suggested five questions that were developed from the proposal. These dealt with:

- Student placement;

- Student learning of mathematics;

- Use of technology in teaching, learning, and assessment of mathematics;

- Classroom research; and

- Faculty development.

The attendees were asked to select the topics they were most interested in discussing. The topics with the most interest were technology, classroom research, and faculty development.

Organizers Co-chairs: James Roznowsk (USA), Low-Ee Huei Wuan (Singapore); Team Members : Vilma Mesa (USA), Steve Krevisky (USA), Auxencia Limjap (Philippines); Liaison IPC Members: Johann Engelbrecht (South Africa).

\section{J. Roznowsk (凹)}

Harper College, Palatine, USA

e-mail: jroznowski@harpercollege.edu

H.W. Low-Ee

Singapore Polytechnic, Singapore, Singapore

e-mail: lowhw@sp.edu.sp

(C) The Author(s) 2015 
To facilitate the discussion of issues related to technology, attendees were asked to answer the following question: What types of technology are available to teach, learn and assess mathematics at your institution? The notes from this discussion follow.

\section{Notes on Uses of Technologies at Non-university Tertiary Institutions}

Types of technologies:

- Graphing calculator

- Computer software (e.g. Excel ${ }^{\mathrm{TM}}$ )

- CAS-good for learning math

- Internet resources

- Projectors and presentation devices

- Online learning platforms (homework problems) - there can be differences between the way in which a topic is explained in online tutoring software and how the instructor teaches, especially when the online tutoring comes with the textbook. In Singapore, instructors typically develop their own materials.

- Course management software (e.g. Blackboard ${ }^{\mathrm{TM}}$, WebCT ${ }^{\mathrm{TM}}$, Angel $^{\mathrm{TM}}$ )

Graphing calculators are handled with a variety of approaches around the world - either not allowed, allowed, or required. Singapore-graphing calculators are compulsory for mathematics at A-levels, and also adopted by high schools offering integrated programmes, the calculators are reset before the start of the A-levels mathematics papers. US - graphing calculator may be required (may be rented) in community college, but then may not be allowed at universities. Canada-required at high school, not permitted at most post-secondaries. Philippines - had assessments both with and without graphing calculators within a single course. Used among pre-service teachers in a course on technology. Worksheets are given to guide the students to gain further understanding from the work done with the handheld calculators.

The discussion related to technology also led to a discussion of developmental mathematics and different terminologies used in different countries or regions. At some institutions "intermediate" algebra and "college" algebra are considered separate topics. Some states in the US are not having developmental math taught in lecture format, and students are being placed in front of computers instead. There is some concern about how well weak students will do under these conditions. There are similar issues in the Philippines. Universities are phasing out foundations mathematics. In Singapore, many of the students who opt to join the five polytechnics are weaker in math. At Singapore Polytechnic, weaker students are given customised CD-ROMs and are required to complete exercises before starting at the polytechnic. They are given assessment test upon arrival, and that determines whether or not they 
are required to attend face-to-face remedial math sessions. Recorded lectures given by selected lecturers to supplement the regular lectures are also provided in Blackboard.

For student teachers in Australia the problem is that when teachers first start, they usually reproduce what they saw when they were in school, so in training teachers, lecturers try to introduce more and different tools that are available.

The second session of DG1 focused on classroom research. Individuals did 5min presentations on the different aspects of classroom research. These included research projects on student/teacher interaction, assessment of student learning, and potential research topic areas. After the presentations, the group discussed the expectations of instructors at their varied institutions with regard to conducting classroom research. At many institutions in the United States and Canada, research is not an expectation of faculty at community or vocational colleges. They are often not given the time or resources needed to do classroom research. In fact, at some institutions, instructors who conduct classroom research may be thought of as taking time away from their assigned responsibilities.

An attendee from Singapore shared information about a new requirement of faculty at her institution to participate in research projects. Questions by others involved faculty reaction to this expectation and professional development for faculty who are new to such research. Information about classroom research in Singapore was distributed to the discussion group attendees after ICME. It was offered as a model that can be adapted to encourage classroom research by instructors at institutions in a variety of countries.

Before the end of the session, participants reviewed ways to continue the discussion beyond ICME 12. The session closed with agreement among attendees that the discussion was of great value and arrangements were developed to make sure a proposal for the continuation of the discussion group would be submitted for ICME 13.

Open Access This chapter is distributed under the terms of the Creative Commons Attribution Noncommercial License, which permits any noncommercial use, distribution, and reproduction in any medium, provided the original author(s) and source are credited. 